\title{
High performance energy conversion of Fe-Pd thin film
}

\author{
Hiromasa YABE, Kazuya OGURI, Haru-Hisa UCHIDA, Yoshihito MATSUMURA, \\ Hirohisa UCHIDA and Yoshitake NISHI \\ TOKAI University, 1117 Kitakaname, Hiratsuka, Kanagawa, 259-1292 Japan \\ TEL: +81-463-58-1211 (ex.4206) FAX: +81-463-58-1812 \\ e-mail:am026429@keyaki.cc.u-tokai.ac.jp \\ (Received 3, October 2001 Accepted 7, December 2001)
}

Fe-Pd alloy thin film prepared by DC magnetron sputtering process shows high performance energy conversion on giant magnetostriction. Fe-Pd thin film has strain changes induced by thermal shape memory effect (TSME) and giant magnetostriction at room temperature. Magnetostriction of $200 \mathrm{ppm}$ at $1 \mathrm{kOe}$ was equal to the strain induced by TSME for $4 \mathrm{~K}$ from $303 \mathrm{~K}$ to $307 \mathrm{~K}$.

Keywords : Fe-Pd, energy conversion, giant magnetostriction

\section{INTRODUCTION}

Fe-Pd alloy thin films prepared by DC magnetron sputtering process show large magnetostriction and high magnetostrictive susceptibility at low magnetic field from earth magnetic field to $0.2 \mathrm{kOe}$ at room temperature. The maximum magnetostriction $(\lambda / /)$ was about $200 \mathrm{ppm}$ and the maximum magnetostrictive susceptibility $\left(\partial \lambda_{/ /} \partial \mathrm{H}_{/ /}\right)$was 0.9 $\mathrm{ppm} / \mathrm{Oe}$ at $0.08 \mathrm{kOe}$. It was the highest value for thin films developed up to 2001. Fe-Pd thin film shows giant magnetostriction at room temperature and strain change of thermal shape memory effect (TSME) against temperature. ${ }^{1}$ Therefore, we have started the study of high performance energy conversion of Fe-Pd thin films.

\section{EXPERIMENTAL}

To get the high magnetostrictive susceptibility, a DC magnetron sputtering was performed to form the film of the fine columnar texture of $\mathrm{Fe}-45 \mathrm{at} \% \mathrm{Pd}$ eutectoid alloy. ${ }^{2-3}$ Controlling the amount of $\mathrm{Pd}$ on the Fe target changed the chemical composition. The samples were deposited about $2 \mu \mathrm{m}$ in thickness on silicon single crystal wafer of (100) plane. Leak rate was $5.0 \times 10^{-7} \mathrm{~Pa} \cdot \mathrm{m}^{3} / \mathrm{s}$ under $3.9 \times 10^{-5} \mathrm{~Pa}$ total gas pressure. The sputtering was performed under $6.0 \mathrm{x}$ $10^{-2} \mathrm{~Pa}$ of Ar gas partial pressure with $200 \mathrm{~W}$ of sputtering power and $3600 \mathrm{~s}$ of sputtering time. The film composition was analyzed by energy disperse X-ray spectroscopy (EDS; JSM-6301F, JEOL) and electron prove microanalysis (EPMA; EPMA-8705, SHIMAZU). The contaminant concentrations were measured by auger electron spectroscopy (AES;
PHI-155-15, ALVAC PHI inc.). The film crystal structure was analyzed by X-ray diffraction (XRD; X'Part-MRD, PHILIPS) and by transmission electron microscope (TEM; H-9000 NAR, HITACHI). The magnetic property was measured by a vibration sample magnetometer (VSM; Model BHV-55, RIKEN). The film texture was observed by means of field emission scanning electron microscopy (FE-SEM; JEM-6000 series WDS/EDS system, JEOL). The magnetostriction $\left(\lambda_{/ /}\right)$of film was measured by a bending method generally used for bi-metal and was estimated by a following equation. ${ }^{4-5}$

$\lambda_{\text {II }}=d \cdot t_{s}^{2} \cdot E_{s}\left(1+v_{d} /\left[3 t_{f} \cdot \ell^{2} \cdot E_{f}\left(1+v_{s}\right)\right]\right.$

Here $t_{s}$ and $t_{f}$ were the thickness of silicon substrate and $\mathrm{Fe}-45 \mathrm{at} \% \mathrm{Pd}$ film, respectively. $v_{s}$ and vf were the Poisson's ratio of silicon substrate and film. $d$ was bending distance of the sample (Fig. 1). $\ell$ is the distance of clamp and spot of laser on film. $E_{s}$ and $E_{f}$ were Young's modulus of silicon substrate and Fe-45at\%Pd film, respectively. The Young's modulus was measured by a nano-indenter method (nano-indenter; ENT-1100a, ERIONIX). The tensile loading stress dependence of magnetostriction on $\mathrm{Fe}-45 \mathrm{at} \% \mathrm{Pd}$ was measured by following method (Fig. 1).

The tensile stress of sample was calculated by following equation. 


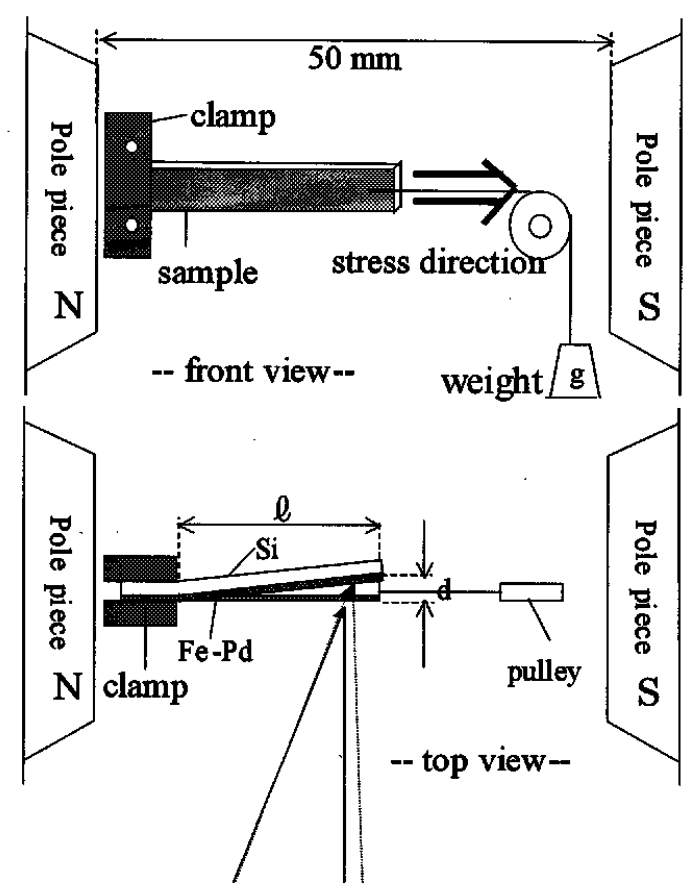

Fig. 1. Schematic diagram of the measurement system.

$\sigma_{s+f}=\left(P_{w}+P_{s}\right) / A_{s+f}$

$\sigma_{f}=\left(P_{w}+P_{s}\right) \quad / A_{f}$

Here $\sigma_{s+f}$ was the tensile stress of sample overall, $P_{w}$ was the load by weight, $P_{s}$ was the load by sample and $A_{s+f}$ was the cross sectional area of sample (film area + substrate area), respectively. $\sigma_{f}$ was the tensile stress of sample nominal and $A_{f}$ was the cross sectional area of film.

\section{RESULTS AND DISCUSSIONS}

\section{Stress dependence of magnetostriction}

Figure 2 shows relationship between the applied magnetic field and the magnetostriction $\lambda_{/ /}$of Fe-45at\%Pd film. Solid and broken lines denote for unloaded and loaded samples magnetostriction, respectively. With the loading stress getting large, the magnetostriction decreased.

Figure 3 shows relationship between tensile stress and maximum magnetostriction $\lambda / / \max$ of $\mathrm{Fe}-45 \mathrm{at} \% \mathrm{Pd}$ thin film. The larger the overall loading stress $\left(\sigma_{s+f}\right)$, the smaller the $\lambda / / \max$ becomes rapidly above loading stress $23 \mathrm{kPa}$. The larger the nominal loading stress $\left(\sigma_{f}\right)$, the smaller the $\lambda / / \max$ becomes rapidly, above loading stress $3.5 \mathrm{MPa}$. We concluded that the large magnetostriction could be obtained above the critical point of loaded stress.

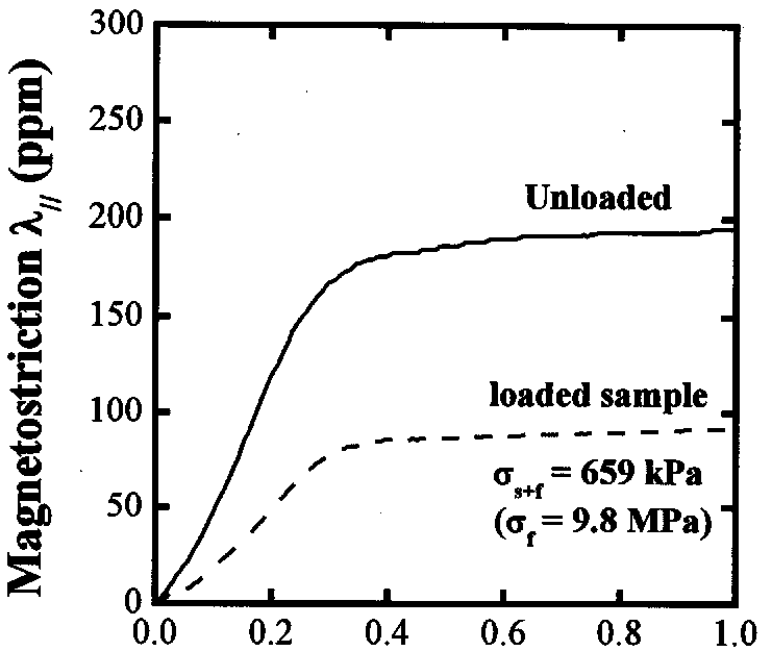

Applied magnetic field $\mathrm{H}_{4}$ (kOe)

Fig. 2. Change in magnetostriction $\lambda_{/ /}$against applied magnetic field $\mathrm{H}_{/ /}$of unloaded and loaded $\mathrm{Fe}-45 \mathrm{at} \% \mathrm{Pd}$ film. Tensile stress $\left(\sigma_{\mathrm{s}+\mathrm{f}}\right)$ was $659 \mathrm{kPa}$.

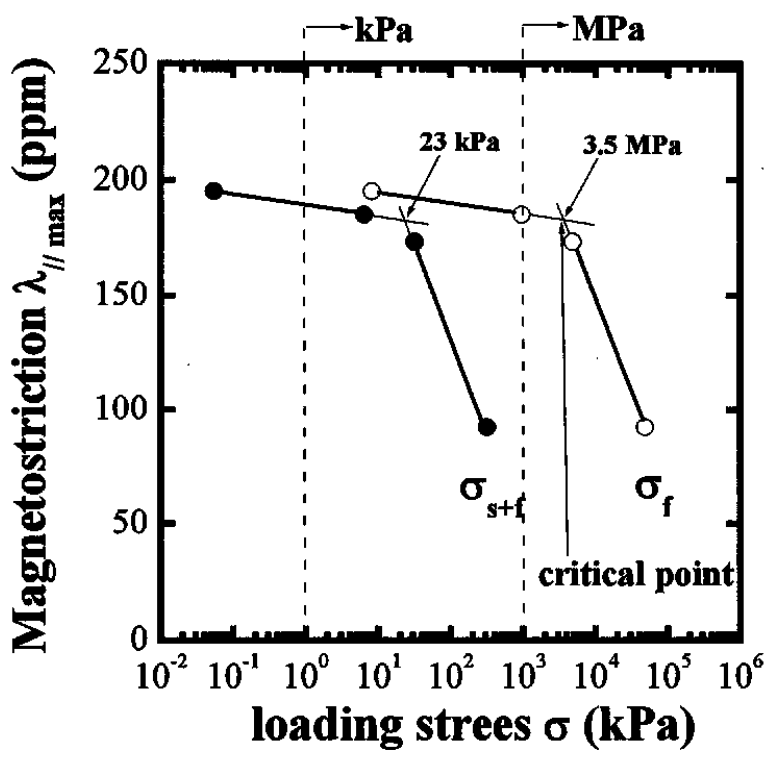

Fig. 3. Change in maximum magnetostriction $\lambda_{/ / \max }$ against loading stress $\sigma$ of $\mathrm{Fe}-45 \mathrm{at} \% \mathrm{Pd}$ thin film.

\section{Thermal shape memory effect of $\mathrm{Fe}-45 \mathrm{at} \% \mathrm{Pd}$ film}

Figure 4 shows relationship between temperature and strain of $\mathrm{Fe}-45 \mathrm{at} \% \mathrm{Pd}$ thin film. The broken line denotes the thermal shape memory effect (TSME) and solid line denotes the giant magnetostriction (GM). The higher the temperature, the larger the strain induced by thermal shape memory effect of $\mathrm{Fe}-45 \mathrm{at} \% \mathrm{Pd}$ thin film.

Magnetostriction of $200 \mathrm{ppm}$ at $1 \mathrm{kOe}$ was equal 
to the strain induced by TSME for $4 \mathrm{~K}$ from $303 \mathrm{~K}$ to $307 \mathrm{~K}$.

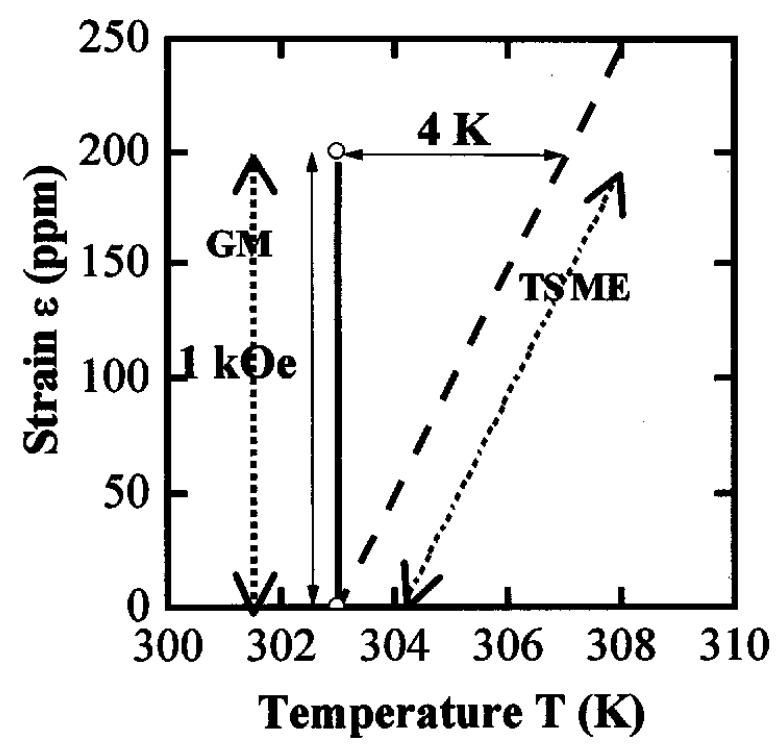

Fig. 4. Change in strain of thermal shape memory effect (TSME) against temperature, and giant magnetostriction (GM) at room temperature of Fe-45at\%Pd film.

\section{CONCLUSION}

Fe-Pd alloy thin film prepared by DC magnetron sputtering process shows the high performance energy conversion on giant magnetostriction. The high responsiveness magnetostriction induced from earth magnetic field to $1 \mathrm{kOe}$. Magnetostriction of $200 \mathrm{ppm}$ at $1 \mathrm{kOe}$ was equal to the strain induced by TSME for $4 \mathrm{~K}$ from $303 \mathrm{~K}$ to $307 \mathrm{~K}$.

\section{REFERENSES}

${ }^{1}$ H. Yabe, K. Oguri, H-H. Uchida, Y. Matsumura; H. Uchida \& Y. Nishi, Journal of Advanced Science, 12, 3, 343(2000).

${ }^{2}$ H. Yabe, R. Fujii, K. Oguri, Y. Matsumura, H-H. Uchida, H. Uchida \& Y. Nishi, Proceedings of 7th International Conference on New Actuators, ACTUATER 2000 107(2000).

${ }^{3}$ H. Yabe, K. Oguri, H-H. Uchida, Y. Matsumura, H. Uchida \& Y. Nishi, International Journal of Applied Electromagnetics and Mechanics, 12, 67(2000).

${ }^{4}$ A. C. Tam \& H. Schroeder, IEEE Transactions on Magnetics, 25, 3, 2629(1989).

${ }^{5}$ M. Wada, H-H. Uchida, Y. Matsumura, H. Uchida \& H. Kaneko, Thin Solid Films, 281-282, 503(1996).

Presented at the $5^{\text {th }}$ International Conference on ECOMATERIALS Oct. 2-4, 2001, Honolulu, Hawaii 